SOUTH EAST EUROPE

Jointly for our common future
SNAPORSE

Planning Aggregates Supply

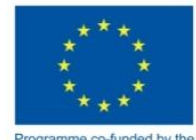

Programme co-funded by the EUROPEAN UNION

How to Build a Sustainable Aggregates Plan

September 2014 

Based on:

The work and experience of project partners within Work Package 6 of the SNAP-SEE Project "Sustainable Aggregates Planning in South East Europe" (SEE/D/0167/2.4/X)

Website: http://www.snapsee.eu

Deliverable of Activity 6.2: Common Transnational Aggregates Planning Scheme

\section{Publication Information}

Editing \& Layout: $\quad$ Foteini Stathogianni, Urška Dolinar

Cover Design: $\quad$ Stelios Mavrigiannakis

Printing: Geological Survey of Slovenia

Year of Edition 2014

\section{Disclaimer}

This SNAP-SEE publication reflects only the views of the authors and the Managing Authority of the South East Europe Transnational Cooperation Programme is not liable for any use that may be made of the information contained therein. CSNAP-SEE project 2014 
Severi Paolo Geological, seismic and soil survey

Bonzi Luciana Geological, seismic and soil survey

Cintoli Stefano Waste and sites remediation, Water and waste public services and ICT

Marasmi Christian Soil and Coast Protection and Reclamation Service

Ratta Manuela Waste and sites remediation, Water and waste public services and ICT

Rizzati Anna Rita Soil and Coast Protection and Reclamation Service

Romagnoli Massimo Soil and Coast Protection and Reclamation Service

Segadelli Stefano Geological, seismic and soil survey

Furin Stefano Consultant at Geological, seismic and soil survey

\section{Reviewers}

\begin{tabular}{ll}
\hline Name & Affiliation \\
\hline Shields, Deborah J., Dr. & Colorado State University, United States of America \\
Agioutantis, Zacharias & Technical University of Crete, Greece \\
Tiess, Guenter & Montanuniversität Leoben (University of Leoben), Austria
\end{tabular}

\section{Acknowledgment}

The SNAP-SEE project partners would like to thank the European Commission for funding this project which led to a fruitful cooperation between partners sharing similar issues and a common vision, and allowed the development of this handbook.

The authors would like to acknowledge the contribution of all partners in the development of the material presented in this handbook.

\section{Digital Object Identifier (DOI)}

doi:10.5474/snapsee-WP6-EN

\section{Citation}

This handbook should be cited in the bibliography with using doi number as follows: Severi et al. (2014), How to Build a Sustainable Aggregates Plan, SNAP-SEE project, http://www.snapsee.eu. doi:10.5474/snapsee-WP6-EN. 


\section{How to Build a Sustainable Aggregates Plan}

1 The state of planning in SEE . .6

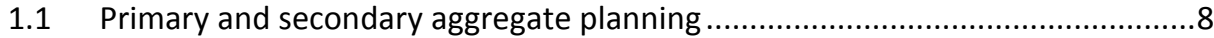

1.2 A centralized approach or a decentralized one? ..............................................14

1.3 On the complexity of developing a mineral resources plan ............................17

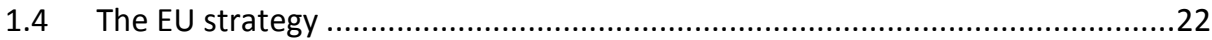

2 A roadmap for planning .................................................................23

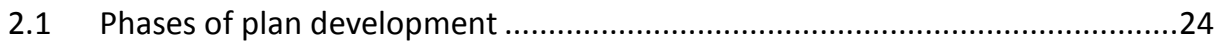

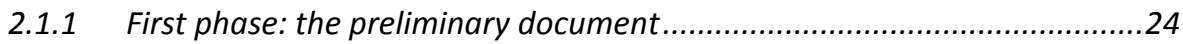

2.1.2 Second phase: Sharing of information ...................................................25

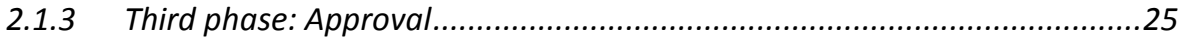

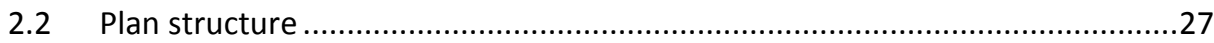

2.2.1 Establish the need of a national plan for aggregate resources ..................28

2.2.2 Integrate the aggregate plan into a more general land use plan ...............28

2.2.3 Establish the ownership of primary aggregates .........................................29

2.2.4 Reference to principles agreed at a European level .................................29

2.2.5 Forecast of future demand of aggregate .................................................30

2.2.6 Identification of priority and protection zones .........................................31

2.2.7 Identification of alternative sources ...........................................................

2.2.8 Definition of criteria and guidelines for local mining areas.......................33

2.2.9 Assure competitiveness of the aggregates industry................................33

2.2.10 Adopt best available technologies along the whole process .......................35

2.2.11 Define criteria for final post-closure utilization ........................................36

2.2.12 Enable coordination between permitting authorities................................37

2.2.13 Permitting procedures should be efficient and effective ............................38

2.2.14 Enforce the need for an environmental balance .....................................39 


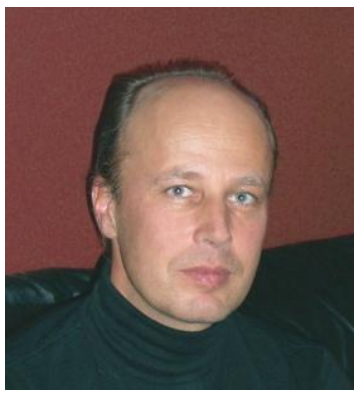

The countries in South East Europe (SEE) are rich in construction aggregates, i.e. crushed stone, gravel, sand and other granular inert materials used in the construction industry; however, these resources are not evenly distributed across the region resulting in abundance in some areas and shortage in others. Furthermore, access to these resources is becoming increasingly difficult due to other infrastructural developments and environmental pressures. As aggregates are heavy and bulky, transport is expensive, therefore access to resources local to the market is crucial. The SEE region will probably require $50 \%$ higher output of aggregates by 2020 in order to build its growing infrastructural needs.

Hence, there is a need to shift to sustainable aggregate resource management (SARM) and provide a sustainable supply mix (SSM) of aggregates to the region to enhance resource efficiency and support sustainable development. SARM is efficient, low socio-environmental impact quarrying and waste management, coupled with broad stakeholder engagement. A SSM is composed of aggregates from multiple sources, including recycled construction and demolition wastes and industrial byproducts (slag), as well as both domestically produced and imported primary materials, that together maximize net benefits of aggregate supply across generations.

Implementing SARM and SSM requires a supporting policy and planning framework. Due to regional differences and historical development, approaches to aggregates policy, planning and management differ at various political scales within and across SEE and in few cases are fully comprehensive. Challenges include policies and plans affecting aggregates management and provision that are distributed among many different legal documents, making coordination and a comprehensive understanding difficult. There is also a lack of coordination on planning for supply from primary and secondary aggregates. SEE lacks sufficient data to support aggregates planning, inadequate capacity and competence for addressing either primary and/or secondary aggregates planning, and insufficient stakeholder participation in the development of aggregates management plans. The SNAP-SEE Project has addressed these deficits in order to foster the growth of a vibrant, responsible and sustainable aggregates industry in the SEE region.

The specific purpose of the Sustainable Aggregates Planning in South East Europe (SNAP-SEE) project was to create and disseminate a Toolbox for Aggregates Planning to help governments and stakeholder in SEE collaborate to enhance their aggregates planning and management processes. SNAP-SEE built on the results of the Sustaina- 
ble Aggregates Resource Management (SARMa) project, a preceding SEE Transnational Cooperation-funded project (http://www.sarma.eu). SNAP-SEE was funded by the EU South East Europe (SEE) Transnational Cooperation Programme (SNAP-SEE, SEE/D/0167/2.4/X) and had 27 partners from 12 SEE countries and Turkey. The University of Leoben, Austria, was the Lead Partner. SNAP-SEE was a 2 year project that ended in November of 2014.

The SNAP-SEE Toolbox for Aggregates Planning comprises 4 products that are interrelated and mutually supporting.

\section{A Vision of Best Practices for Aggregates Planning in South East Europe}

The 'Best Practices' document presents a Vision for a transition to integrated, comprehensive sustainable planning in SEE. It includes discussions of the issues that need to be addressed, interim steps that can be taken toward more sustainable planning, and a review of the components a sustainable plan should contain.

\section{How to Build a Sustainable Aggregates Plan}

This 'How to' document represents a roadmap for planning, including discussions of the planning process itself and its various steps. Examples of well written planning modules are provided that embody the principles, approaches and actions necessary to achieve the goals of the Vision laid out in the Best Practices report.

\section{Consulting Stakeholders when Applying Best Practices in Sustainable Aggregates Planning}

The 'Consultation' document provides a step-by-step guide for how to plan and conduct stakeholder consultations so as to ensure that industry, government, nongovernmental organizations and civil society can provide input to and participate in the planning process. Capacity building materials are also provided.

\section{Data and Analysis in Support of Best Practices in Sustainable Aggregates Planning} The document discusses the various types of data that provide essential background information for the planning process. Data definitions, significance, availability, structure and needs are addressed. Methods for validating and analysing data are presented, including approaches to demand forecasting.

Project Coordinator

Guenter Tiess

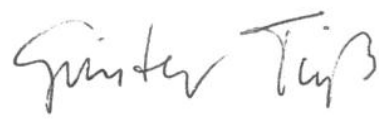

Montanuniversität Leoben

(University of Leoben) 


\section{The state of planning in SEE}

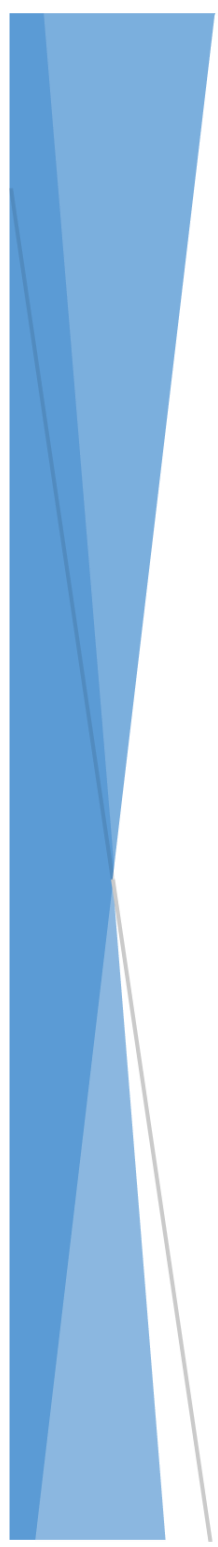

Assuring sustainable supply of aggregates resource is an important challenge due to their limited availability when aiming at sustainable regional development. Due to the regional differences and historical development, there are diverse approaches to aggregates policies, planning and management in South East Europe, which is hindering resource efficiency and economic development in the region. The objective of the SNAP-SEE project is to facilitate improved aggregates planning in South East Europe to achieve this goal.

\section{6}


One of the intrinsic characteristics of existing mineral plans across EU is the disaggregation of some policies among different Authorities, different sectorial plans and different advancement levels. The diagrammatic approach followed in this chapter wants to highlight the actors involved in the planning procedure, and the relationships among the legislative tiers and authorizations documents they produce. This approach complements the analyses provided in Horváth et al. (2014) and by Agioutantis et al. (2014), both included in this Toolbox.

In most Member States a specific Mining Law covers the extraction of state-owned minerals. Many South East Europe (SEE) countries have also a mineral policy. Sectorial policies are declared governmental objectives, fostering economic, social and usually environmental development of a country. Policies define the national strategy and are followed by the development of plans. Planning is thus the creation of formal procedures to be followed to achieve objectives. Plan administration constitutes the mandate of management bodies.

Whereas a mining law exists, the adoption of specific policies and plans are not so widespread, but the development of these plans is an on-going process. This is a great opportunity to adopt sustainable approaches in the region.

An example of this on-going process are the developments in Montenegro (Figure 1): The Spatial plan of Montenegro for the period until 2020 is the document laying down long-term fundamentals for the organization and landscaping of the country until 2020. The State plan is a general one, but when it comes to mineral resources one of the points of the Plan requires an evaluation of existing mineral resources in the country, an estimation of the reserves, the location/sites of the mineral resources deposits as well as the location/sites where exploitation was performed so far.

In this country planning related to the production of aggregates is covered with two separate laws: the Law on concessions and the Mining law. The most important act regarding the aggregates planning is the Mining law, which defines the obligation for adoption of the state plan of mineral resources exploitation, which comprise of a general plan and a plan for exploitation of particular mineral resources. Also the Law on concessions defines that concessions, which is the only way for obtaining rights for exploration and exploitation of mineral resources, are awarded on the basis of the long-term plan adopted by the Government. Exploration and exploitation of mineral resources in Montenegro are the subject of concessions given by the State to the companies on the base of Annual concessions plan. An annual plan is adopted by the Government of Montenegro after a public hearing, conducted by Ministry of Economy when it comes to technical-building stone (crushed stone), and sand and gravel not quarried from rivers, and by the Water Administration when related to river 
gravel and sand deposits. The concessions plan, among other things, identifies the location on which to give concessions.

The National Waste Management Policy, the National Strategic Master Plan for waste management, and the Study on Revision Necessity Assessment of the Waste Management Strategic Master Plan in Montenegro and the Recommendations for Organization of Waste Management Affairs for the period until 2030 should also be mentioned. The law on Waste Management represents the legislative framework in the waste management area. The law was adopted in 2011. Also, some supporting legislation has been adopted.

Therefore, the long term planning and future integration of different sources of aggregates is feasible, and legislation that defines the need of aggregates management does exists, but at the moment Montenegro has not yet developed a specific aggregates plan. Plans devoted to mineral resources, first among them the state plan of mineral resources exploitation, leads to resource efficiency and in theory can be compatible with the SARM and SSM goals.

\subsection{Primary and secondary aggregate planning}

The necessity to reduce the use of non-renewable natural resources and, at the same time, to minimise the negative impacts due to production and management of the construction sector waste has promoted an increasingly higher interest towards recycling, especially with respect to the European Commission. Thus, the option to recover some fractions of waste and re-insert them into the productive cycles under the forms of products or raw materials seems challenging.

Cultural resistance to the use of recycled aggregates, due to their waste origin, is one of the main obstacles for the development of the aggregates recycling industry. In order to definitely eliminate all user prejudice it is necessary, pursuant to the 2008/98/EC Directive, to define as soon as possible the criteria by which waste changes into useful material (Bressi et al., 2011).

After the secondary aggregates resources lose their "waste" status they can be considered as an alternative source of materials for specific uses. Due to this "change of state", as of today in many SEE countries primary and secondary aggregates policies and plans do not reside within a single document; they are distributed among many different legal documents, making coordination and a comprehensive understanding difficult. Also, there is a widespread lack of coordination on planning supply from primary and secondary aggregates.

Since the secondary aggregates are the key to replace the use of non-renewable aggregates and reduce the impacts on environment, planning authorities should identify the volume of secondary resources that could be used as aggregates. In particular, 
the use of recycled aggregates has been increasing as a number of countries have been adjusting their objectives and policies in aggregate planning (Agioutantis et al., 2014).

SEE states are in an on-going process to establish inventory of different secondary aggregates, or at least a register of the potential sources of such aggregates. Many examples exist, but at the moment some of the most complete records of potential sources are collected by Trento Province (Figure 2) and Croatia (Figure 3) that also estimate or acquire data for aggregates excavated from civil works, together with C\&D waste, extractive by-products and industrial waste, whereas Slovenia (Figure 4), Serbia, Slovakia and Austria collect percentages on the amount of recycled secondary aggregates product.

\author{
Acronyms used in the national schemes (Figures 1-9): \\ Inter. Com.: Interdisciplinary Committee; \\ S.E.A.: Strategic Environmental Assessment; \\ E.I.A.: Environmental Impacts Assessment; \\ M.I.E.: Ministry for Industry and Economy; \\ M.o.E: Ministry of Economy; \\ N.C.L.: National Center for Licensing;
}

A larger version of the schemes presented in the following pages are available on SNAP-SEE project website www.snapsee.eu. 


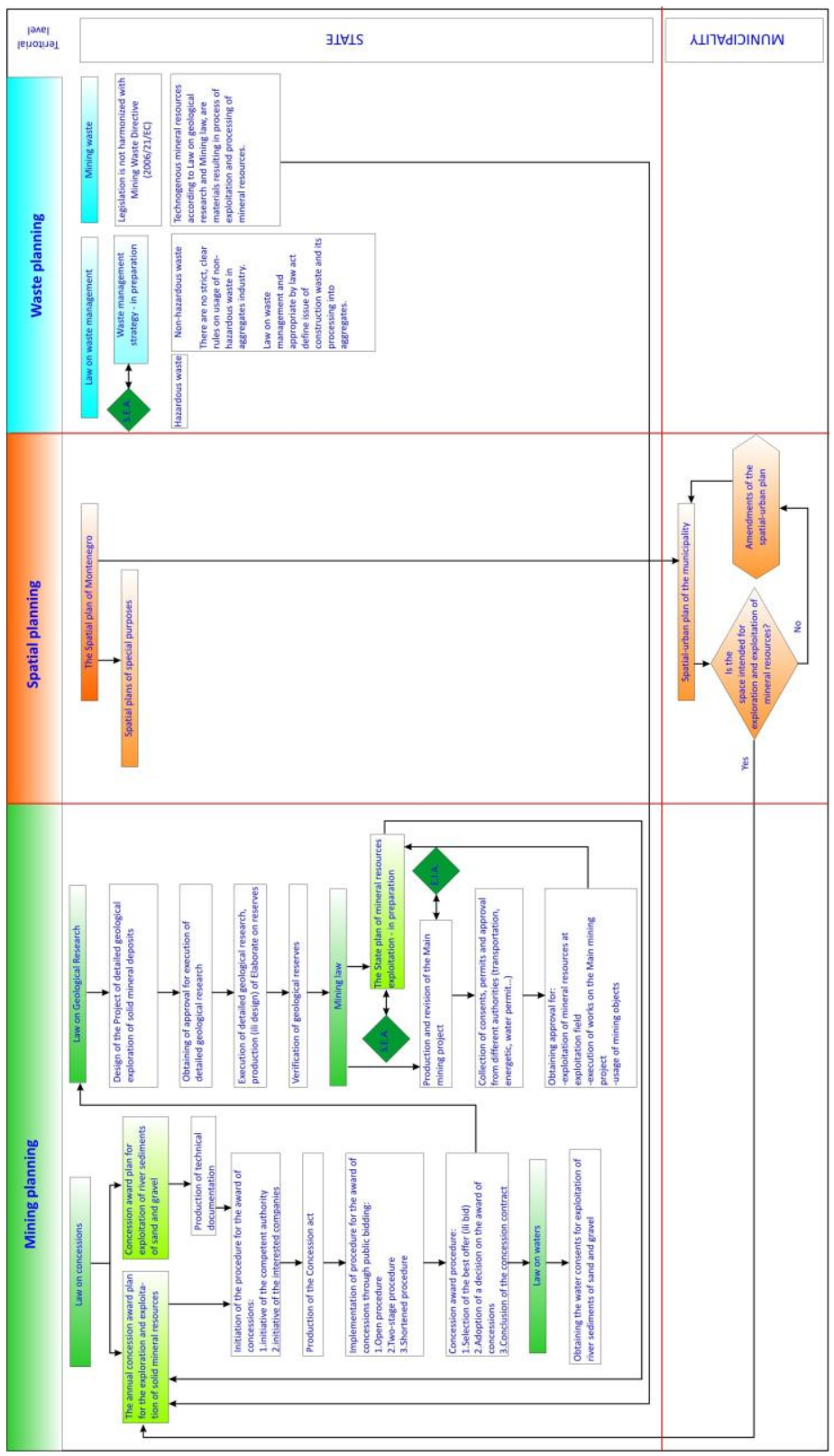

Figure 1 - The relationship between spatial planning and mining procedures in Montenegro. 


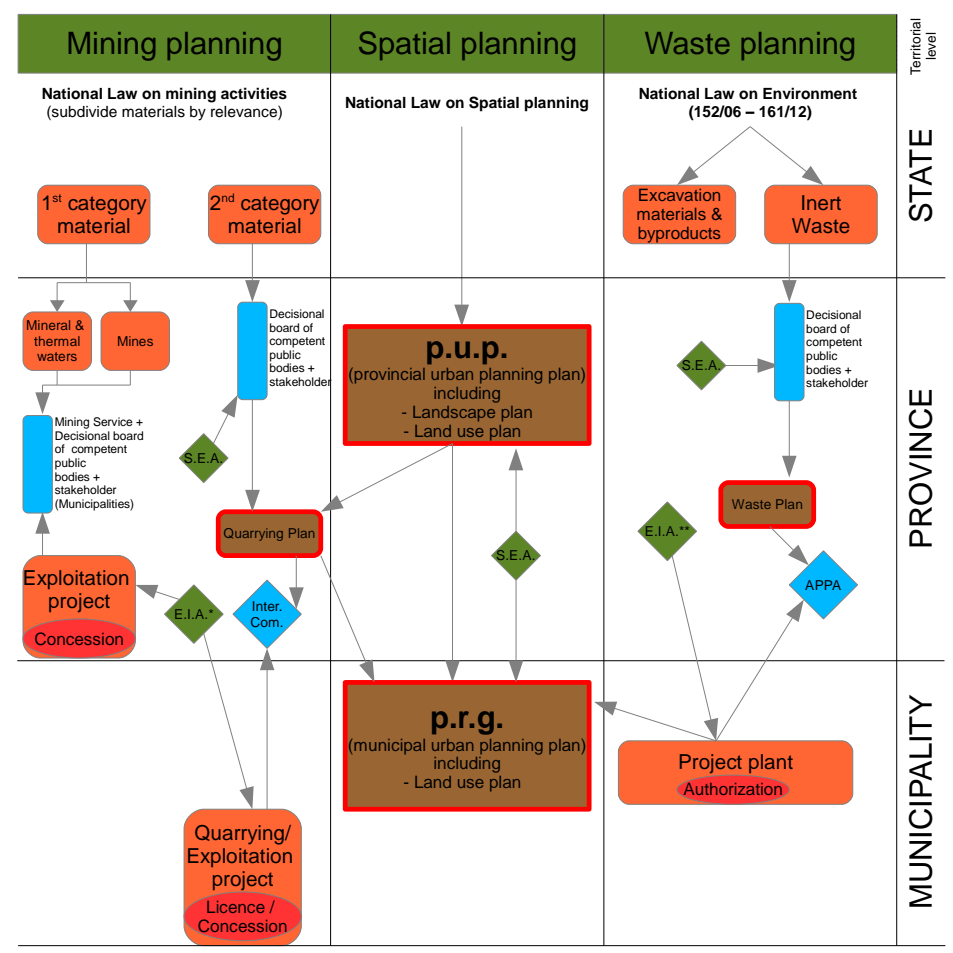

Figure 2 -Spatial planning in Trento province, Italy: Mining planning and spatial planning procedures are comparable to those at Emilia-Romagna province (see Figure 6), whereas a waste plan has been adopted earlier. An Interdisciplinary Committee in Trento province is established by provincial law, assessing all the exploitation projects in the Province. The committee is called by the Mining Service and is composed by APPA, Environmental Assessment; Service, Forest and Fauna Service, Geological Service, Urban Planning Service and an External Expert (chosen by the industrial association). It verifies the projects through a positive or negative binding opinion, but the Municipality is in charge to release the licence or the concession according to this opinion. *: the provincial law LP 28/1988 determines the limits, beyond which an environmental impact assessment is required. For extractions over $200.000 \mathrm{~m}^{3}$ of materials a screening procedure is needed, instead for extractions over $500.000 \mathrm{~m}^{3}$ (or area larger than 20 hectares) an E.I.A. is required. ${ }^{* *}$ : the project is subjected to an E.I.A. focused more on the waste management (localization criteria, waste types, treatment, noise and dust barriers...). The arrows, that aim from the bottom to the top, highlight that the procedure to achieve a licence, a concession or an authorization starts from the quarrying companies: the requests should be in agreement with the instruments brought by the plans and with the plans themselves (e.g. localization). The Municipalities receive the quarrying demands and submit them to the Mining Service, which calls the Interdisciplinary Committee. For the first category material the companies should present their projects at provincial level (Mining Service), the interested Municipalities are involved in the decisional process. 


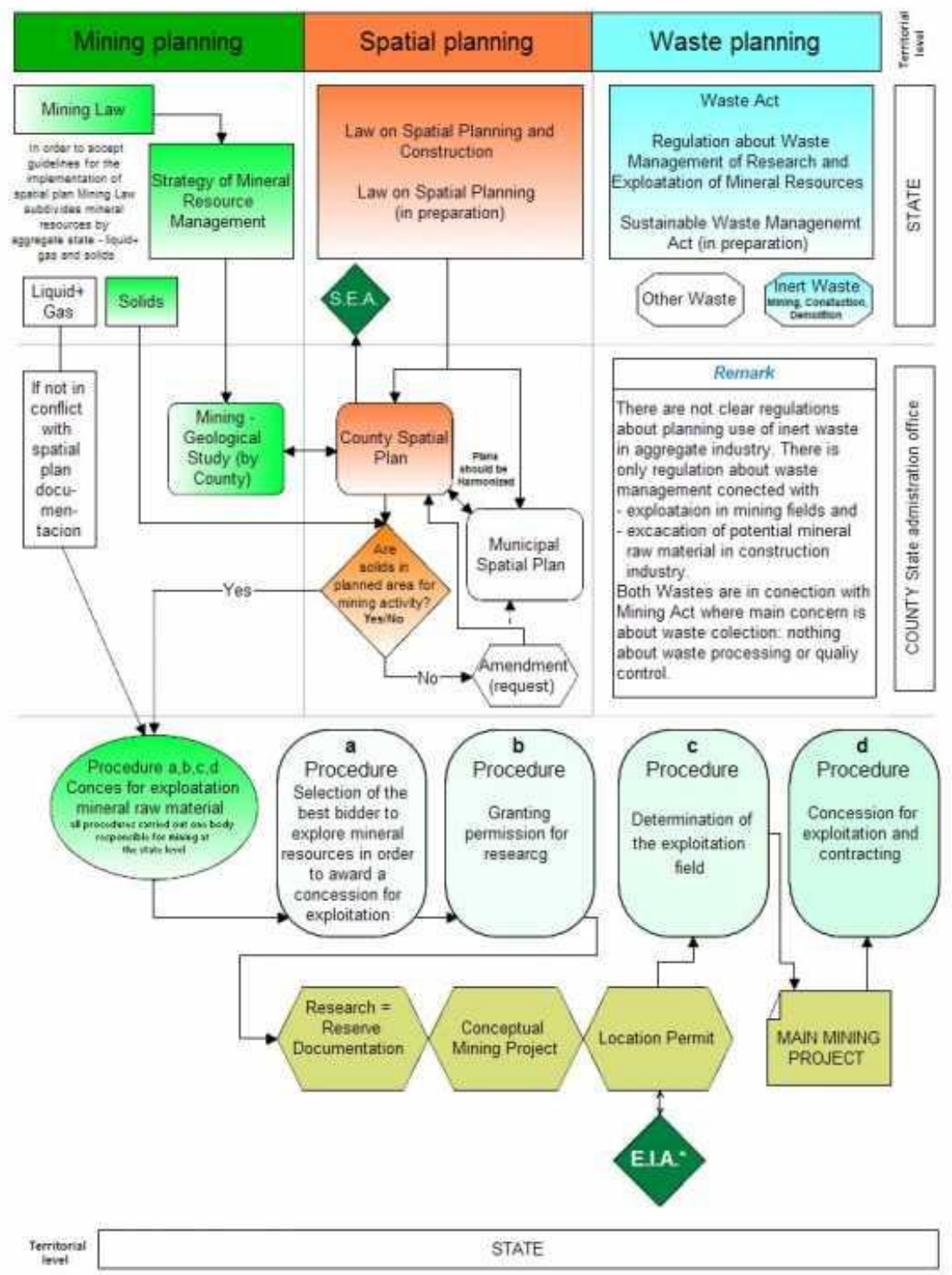

Figure 3 - Spatial planning and its interaction with mining laws and future waste management act in Croatia. *: Environmental Impacts Assessment in Croatia is obligatory for all operations in mining industry. 


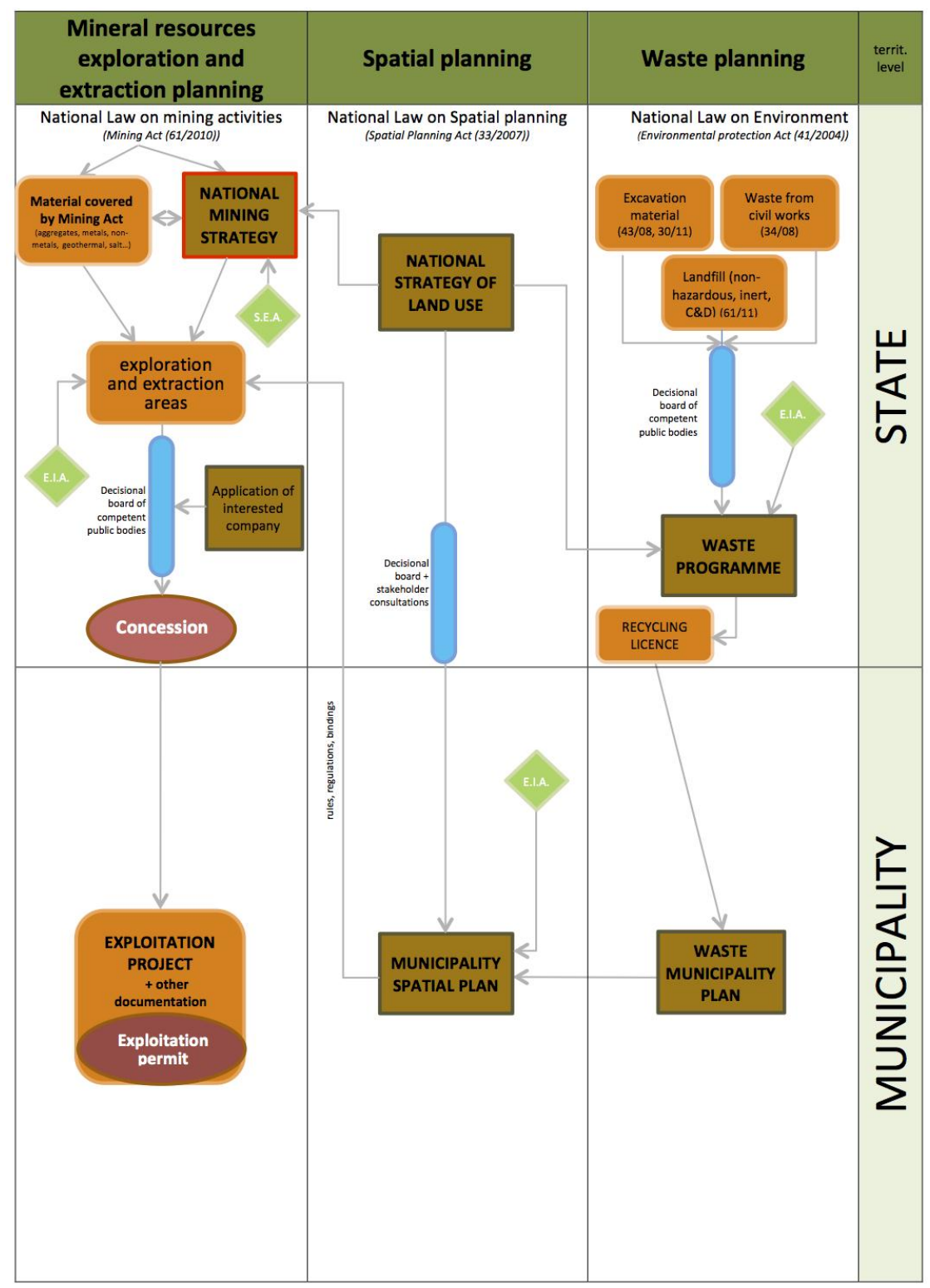

Figure 4 -Planning for aggregates, waste and their interaction with spatial planning in Slovenia. 


\subsection{A centralized approach or a decentralized one?}

The experience in SEE shows that many countries delegate the implementation of their minerals policy to lower tiers of government. In many countries municipalities play a key role in the permitting procedure; although their role in plan development is not clear or not defined.

Many countries follow a centralized approach, e.g. Albania, Slovenia, Serbia among others. A centralized approach has many advantages, including the easiness of producing a coherent national strategy without the risk of a lack of harmonization among second-level administrative bodies. Another advantage is usually the lack of complexity in the permitting procedure that may be granted by a single authority.

As an example, in Albania the action plan for implementation of mining strategy take place and is described on National Mining Law (Figure 5). The action plan defines the implementation of medium-term strategy of a mining mineral planning document, compiled based on mining strategy and it is valid for a 3-year period. The action plan includes:

- Directions for the development of the mining sector;

- Promotion of mining areas for which mining licenses will be awarded through a competitive process or open procedures;

- Promotion of mining areas, based on mining digital map, which is compiled within one year from the entry into force of this law and constantly updated;

- Programming of basic geological research activities;

- Prediction of the total annual product on the mining sector;

- Capacity building for mining activities;

- Rules for the implementation of safety measures and safety of employees;

- Regulations for environmental protection, landscaping and rehabilitation;

- Hazardous areas, where mining activity and granting of mineral rights is prohibited;

- Tables with the minimum values of surface area allowing mining permits, the minimum value of the investment for mining permits search and discovery, and minimum values for the production of mineral exploitation permits for competitive areas and open areas, according to the group of minerals.

In Albania (Figure 5), the selection of areas and the criteria for determining the minimum size, minimum investment value and the minimum value of production is drawn up by the Ministry and is approved by the Council of Ministers. When implementing the action program, the annual mining plan is adopted, which includes the definition of mining areas ready to be awarded for mining rights for the respective year. The annual plan is developed by the responsible authorities on mining and ap- 
proved by the Minister, through a consultation process at a central level (with the relevant ministries Ministry of Environment; Ministry of Tourism; Ministry of Transport; Ministry of Agriculture, Ministry of Defence) and at a local level with the respective local government units. Any change or addition to the annual plan approved and published by the same procedure.

A centralized approach in large states may hinder the involvement of local communities during the development of the plan. In addition such an approach and should usually deal with sensible differences in primary and secondary aggregates availability, and a less homogeneous development (and thus a different demand rate) among different areas of the state.

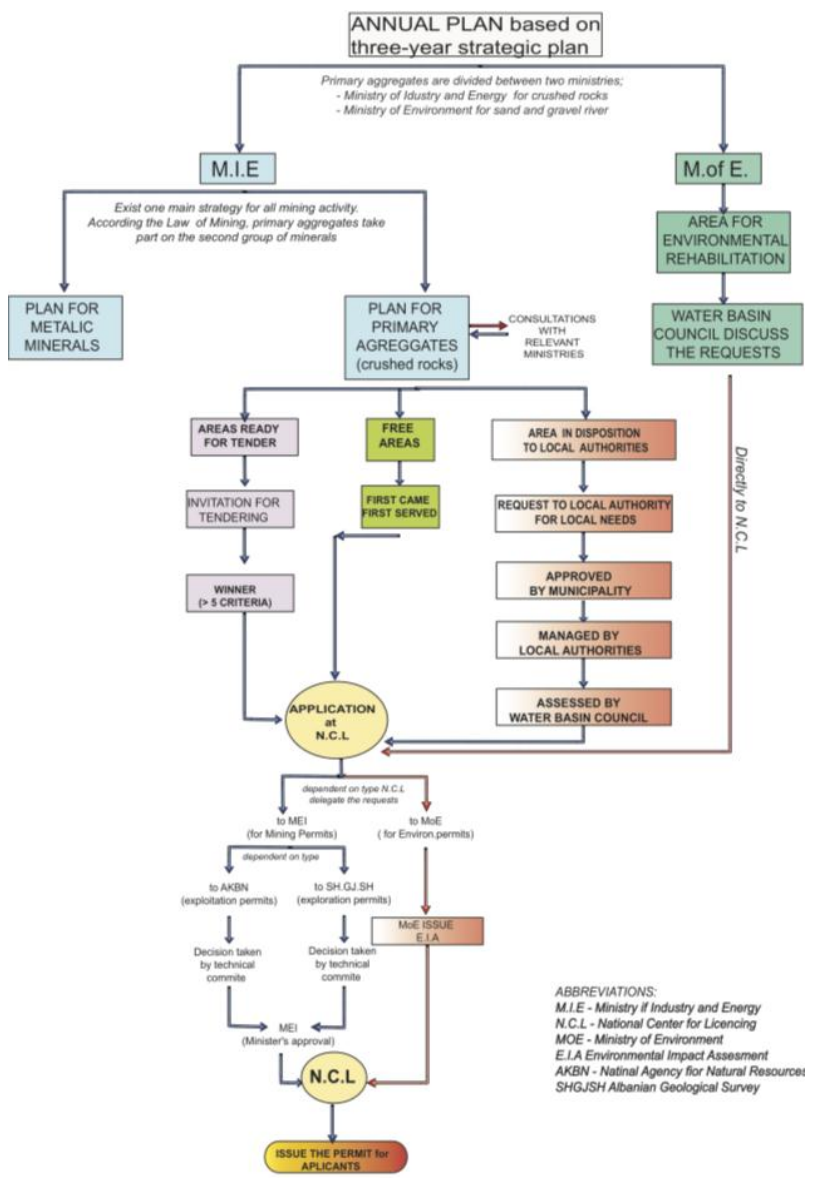

Figure 4 - Mining plan and permitting procedure in Albania. AKBN: National agency for Natural Resources; SHGJSH: Albanian Geological Survey. 
Larger states have a more complex interrelationship among national and local plans: many examples are available including Italy (Figure 6), Greece (Figure 7), Hungary (Figure 8), and Austria. In Italy land use planning is delegated to first level administrative bodies (regions); they have the capability to further delegate some of the administrative functions to a second level of administrative bodies (provinces). This is the case of Emilia-Romagna Region that in 1991 delegated the development of mining plans to its provinces, in the spirit of a more decentralized and collaborative management of public resources, while retaining a central coordination role. The provincial mining plan takes into consideration several pieces of information, rules, bindings, and regulations coming from other regional and provincial spatial plans and data sources. The Region provides information on geological resources, approves the plan and keeps a register of identified areas suitable for excavation.

A decisional board of competent public bodies and stakeholders drives the process that delineates the Province mining plan (generically defined as wide-area mining plan), and a Strategic Environmental Assessment verifies it. The provincial mining plan contains:

a) a quantification of sub-regional scale of the needs of different materials for a period ten years;

b) an identification of the provincial poles for aggregate extraction and the definition of criteria and guidelines for the location of mining areas of municipal significance based on the resources used (as quantified in [a] above), the factors of nature and landscape, the needs for farming soil and the underground water table;

c) the criteria and methods for cultivation and final recovery of new quarries and for the recovery of the already abandoned quarries;

d) the criteria for the post-closure utilization and/or restoration for natural and public use.

The plan is accompanied by a study of environmental balance that verifies the environmental compatibility of mining on the basis of current legislation. The study of environmental balance sheet contains the identification of areas of high environmental sensitivity, the reasons for the choices provided also in relation to possible alternatives. The provincial mining plan has a term of ten years, after which it must be reviewed, updated and accepted at the Municipality level, within two years from its approval. The municipality mining plans describe in more detail the framework defined by the Province plan. These plans, finally, identify the areas potentially suitable for exploitation by private entities; provide an environmental impact assessment, the measures to reduce impacts expected and the recovery plan. The Region has a role in checking and regulating the technical compliance of the provincial wide-area mining plan with the provincial land use plan and with regional plans and rules, eventually 
requiring specific changes. Similarly, the public responsibility in Austria is divided between the four levels of government in the federal structure - the Federal Government, Federal States (Länder), Districts and Municipalities. The federal government, specifically the Ministry of Economy, Family and Youth, is responsible for the overall raw materials policy, but spatial land use planning is the responsibility of the federal states.

As a result, each of the nine federal states has its own regional planning laws, which in the past had differing provisions in relation to the safeguarding of mineral resources. As work on the Mineral Resources Plan progressed, and with the assistance of the federal government, most of the states have developed sectorial regional development plans for raw materials and have designated "suitability zones" or "mineral safeguarding areas". The developments at the federal state level should take the local interests into account. Furthermore, as a result of the Mineral Deposits Act.33 of 1947, the Geological Survey and the Mining Authority are obliged to cooperate in surveying the territory for any minerals. The long-standing and constructive cooperation developed on the basis of this requirement has provided an excellent basis for establishing high quality minerals-relevant information.

The given examples demonstrate how the centralised nature of the plan reflects the national organization of spatial planning. This is desirable when the country is remarkably smaller than $100,000 \mathrm{~km}^{2}$ since it allows for a complete overview of all the aggregate sources and better forecasts. There are many cases, however, where either the nature of the plan has already been established by national laws or a plan needs to be territory specific in order to better focus on regional issues (as an example please compare the Bosnia and Herzegovina scheme, Figure 9).

\subsection{On the complexity of developing a mineral resources plan}

Aggregate resources planning is usually included in a more general mineral resources plan. The Austrian Mineral Resources Plan has been cited as best practice in land use planning at a European level on a number of occasions. Various features of the Plan, including its systematic approach, constitute good practice and further detail has recently been provided on its implementation at a local level (CSES, 2014). 


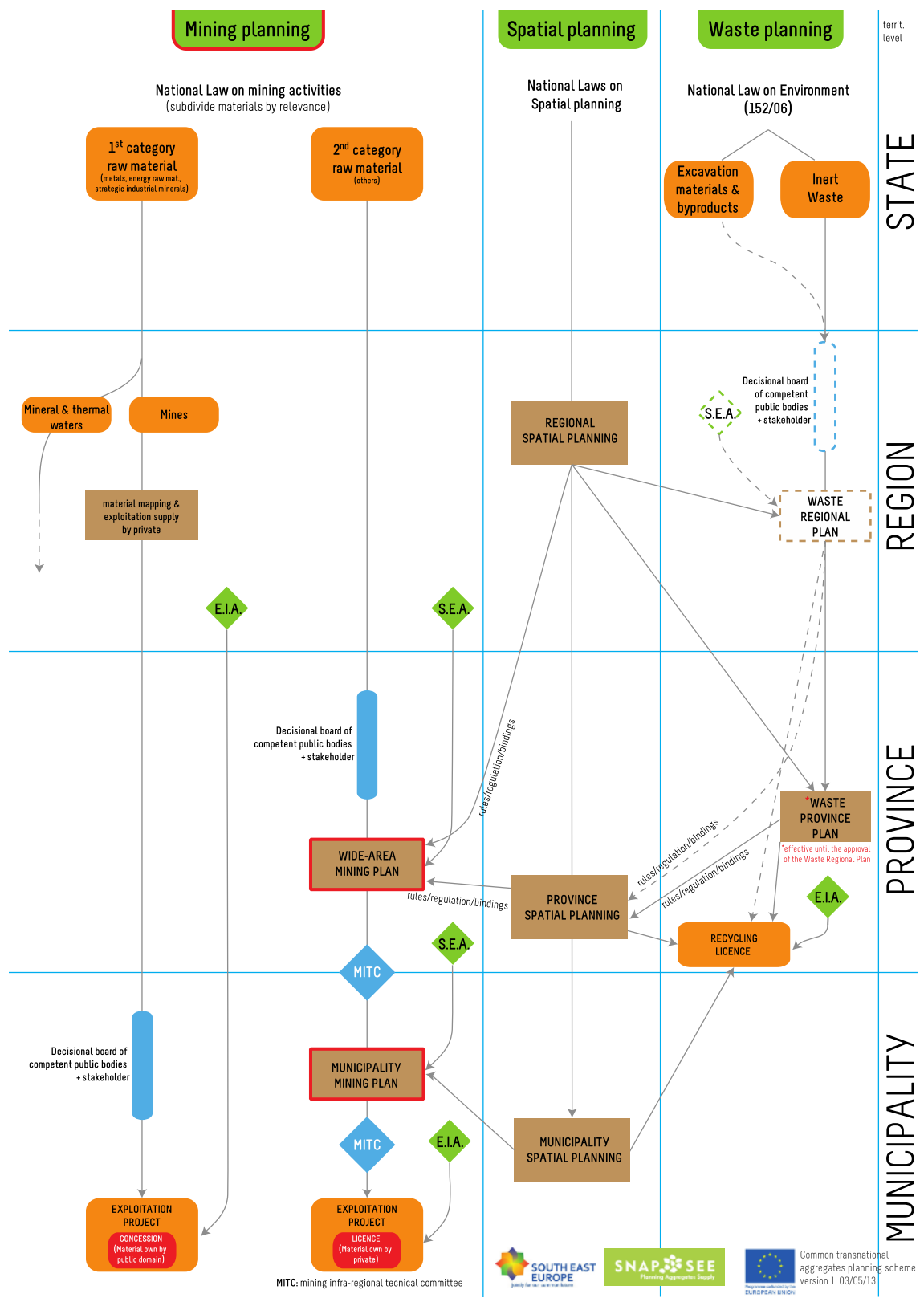

Figure 5 - Regional planning related to aggregate supply: the example of Emilia-Romagna Region in Italy. 


\section{Planning Scheme of Aggregates in Greece (2014)}

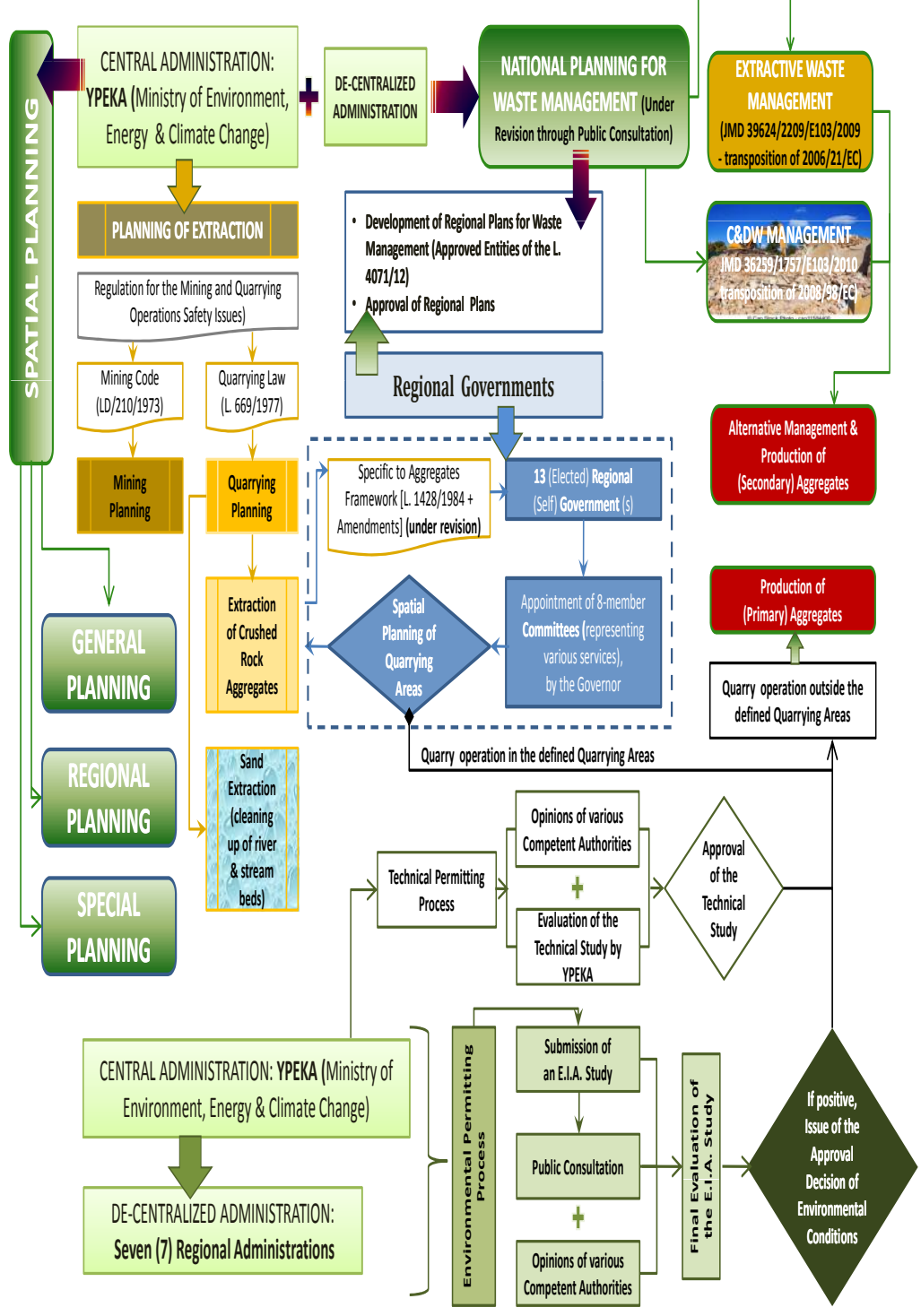

Figure 6 - Planning scheme of aggregates management in Greece 


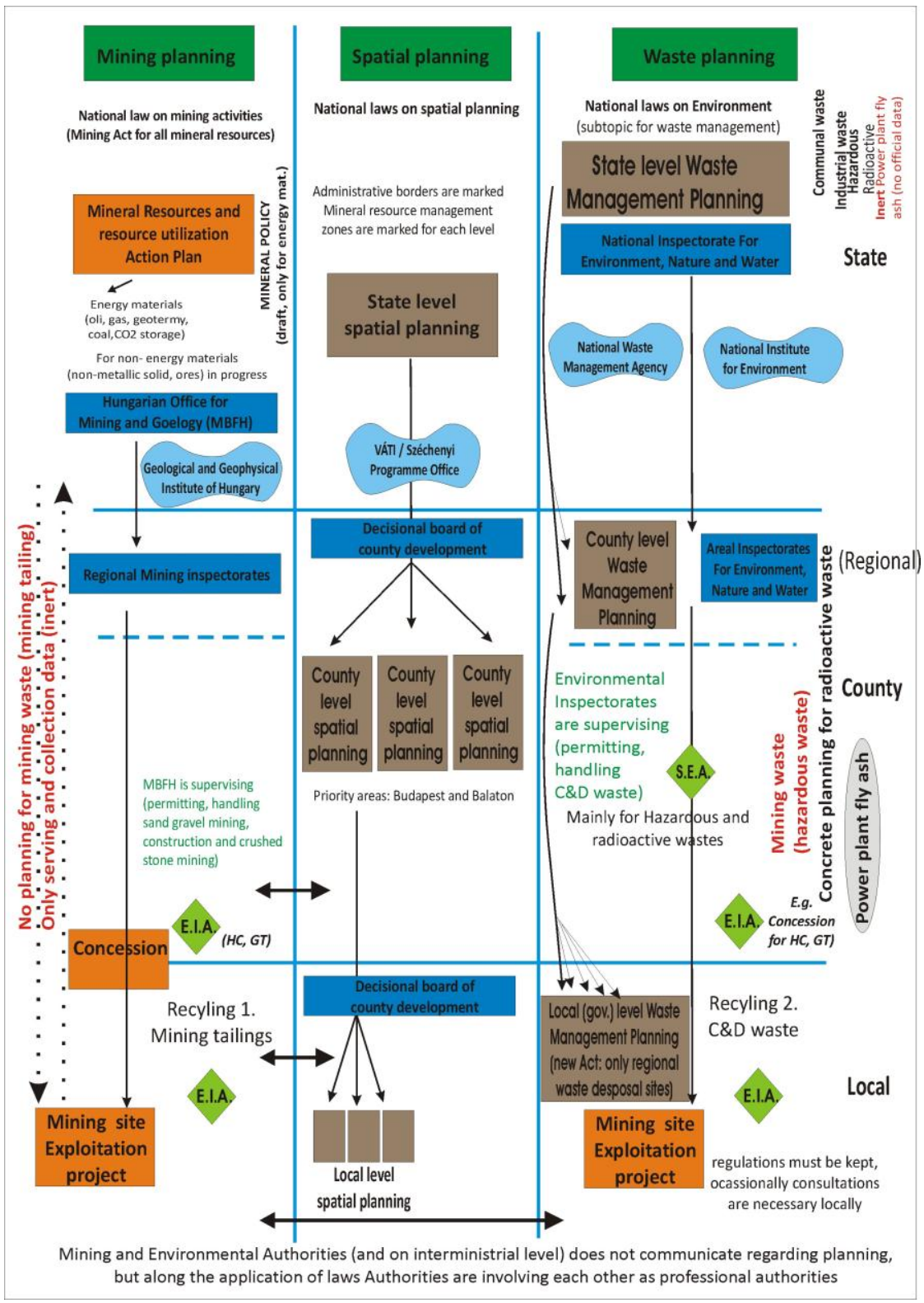

Figure 7 - Structure of mining, spatial and waste management plans in Hungary 


\section{Aggregates planning scheme in Bosnia and Herzegovina and Herzegbosnian canton}

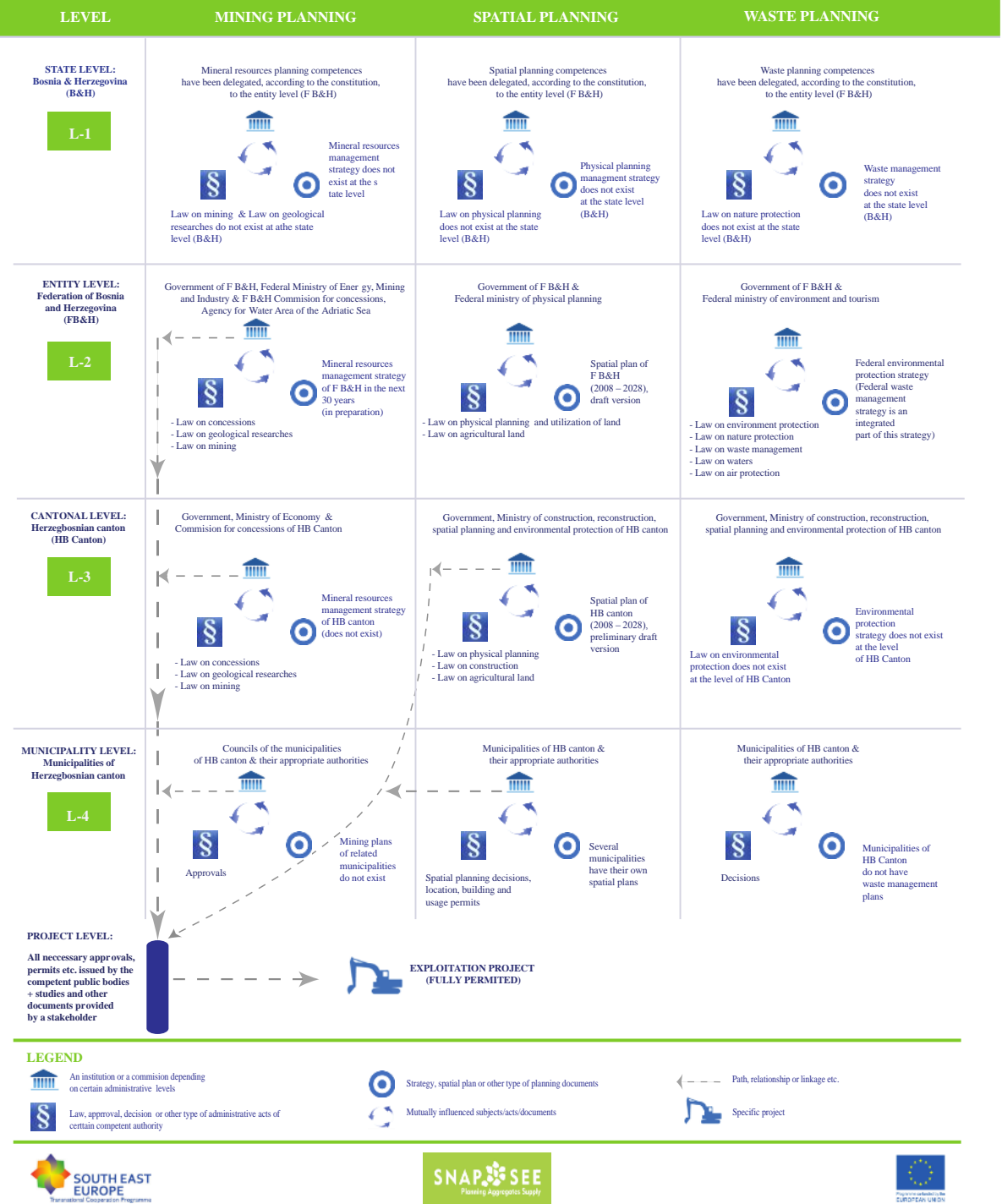

Figure 8 - Aggregates planning at different administrative tiers in Bosnia and Herzegovina and Herzegbosnian canton. 
The first lesson that may be learned from the Austrian experience is that the development of the plan may require a long time, since it requires an accurate and objective synthesis of available data on mineral occurrences, a precise mapping of accessible resources and an analysis of their conflicts with other land use strategies. As a first approach mineral occurrences worthy to be protected because of quality and quantity were identified in conflict-free areas. These occurrences where then handed over to the competent authorities of the provinces to declare them as raw material safeguarding areas in land use planning. By respecting raw materials safeguarding in land use planning it was possible to make sand and gravel available for more than 50 years and crushed stone for more than 100 years for most supply regions (Weber 2012).

The Austrian Mineral Plan took almost ten years to be completed. It began with an amendment to the Mineral Raw Materials Act in 2001 and ended in 2012 with the publication of the document (Weber 2012). The purpose of a plan is to perform the groundwork required in preparation for activities by private enterprises.

\subsection{The EU strategy}

The studies and the debate promoted by the SARMa and SNAP-SEE projects have highlighted how the development of national policies may lead to disaggregation and inhomogeneity, leading to cross-border issues due to different legislative frameworks. Nowadays there are still too many differences among mineral policies and plans at various political scales within and across the region. The European Union should progressively integrate and homogenize national policies and plans trough the definition of common strategies. It is worth noting that aggregate resources, being considered one of the raw material to be secured for the next generations, are encompassed in the "Europe 2020 Strategy".

Despite the fact that not all SEE countries are part of EU, the principles posed by the EU2020 strategy pillar on resource efficiency are a mandatory goal in the whole region, due to the non-renewable nature of primary aggregates resources and because of the impacts that excavation and inert waste dumping have on the environment and on the society. 


\section{A roadmap for planning}

The development of a plan should start from a national-level strategy and must follow the obligations defined by national laws.

The procedure for preparing the plan is usually susceptible to adaptions in order to customize it to each specific sector. Exploitation of mineral resources including natural aggregates may generate impacts on the land and requires a balanced involvement of the stakeholders in order to highlight the needs and the benefits of a sustainable approach. The development of a strategic plan requires consideration and articulation of values and priorities; the plan should reflect views expressed by all those involved in the process. States that have successfully designed and adopted plans included all those interested in the strategic planning process. 


\subsection{Phases of plan development}

\subsubsection{First phase: the preliminary document}

The first step in the development of a plan is to analyze the role of the entity in charge of plan development, and its goals (Figure 10). In order to answer the question of "what we should work with" the strengths and weaknesses of the entity in charge of aggregates planning should be determined, with the objective to capitalize on the strengths. A useful reading, at this point, may be with "The special characteristics of aggregates planning" in Horváth et al. (2014), section 1.2.

The second step is to define a vision. Horváth et al. (2014) specifically addresses this aspect in part 4 of the booklet "Joint Vision on the Optimal Contents of Aggregates Plans" providing a good example of a vision at SEE level that may be adopted also at national level. As the articulated vision stems from the values of those involved in the process, it is essential that this step involves all of those who will have a stake in the achieving the vision.

The third step involves the articulation of goals identified by the vision. The goals may be several and eventually conflicting, like economic growth, abundant supply of resources and environmental safeguarding. For each goal, planners must address the means of reaching their goals. This step involves articulating strategies for achieving results. Strategies should reflect the strengths and weaknesses of the entity engaged in the planning in order to not be limited e.g. by lack of data or by the capacity to implement the plan in the future.

The fourth step should focus on the definition of a knowledge framework to support the strategies identified in the third step. Data are an essential element to provide a

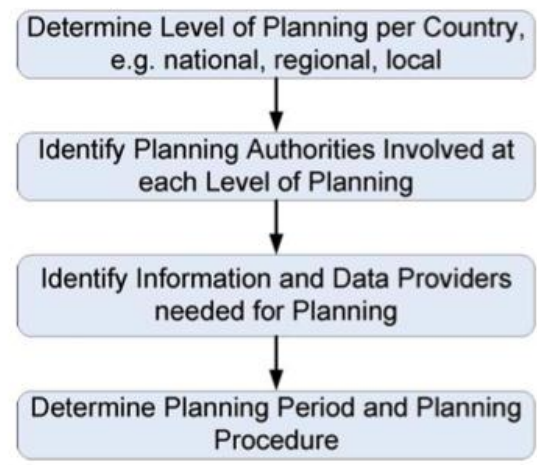

Figure 10 - The first steps in the development of a mining plan, after Agioutantis et al. (2014). 
sustainable plan. Without data a plan cannot provide forecasts and cannot be updated according to changes in the demand. If data are not regularly collected they should, and the plan should assess the need of such data. Since a plan should define some methods to measure the achievement of goals, data are also a fundamental aspect of monitoring and alternative scenarios evaluation. For a complete overview on this step, including insights on life cycle analysis as a tool to evaluate potential scenarios, we invite the reader to read Agioutantis et al. (2014), included in this toolbox.

\subsubsection{Second phase: Sharing of information}

Stakeholder involvement should thus take place during the early phases of plan development (Figure 11). Guidance on how to organize stakeholder involvement is provided by Dolinar et al. (2014), included in this toolbox. Stakeholders should be educated, trained to deal with the complex interrelationship between natural, economic, social issues related to primary and secondary aggregates supply. For this reason it is important to set up meetings and workshops in order to prepare the stakeholders for this subject.

The plan should be then developed through an iterative process in order to resolve eventual conflicts among actors and goals. A hierarchy of goals may help in this case, as well as a very clear and succinct list of them in order to not overwhelm agencies, but also industry with too many details on data collection and reporting.

State officials and managers of public programs are often faced at this point with the need to negotiate between conflicting mandates and goals when articulating strategic plans. In such cases, legislation may have been drafted with input from numerous representatives with conflicting views. As public managers develop strategic plans, they should recognize that programs might have conflicting mandates and be explicit about what the agency can and cannot do in light of the mandates.

\subsubsection{Third phase: Approval}

After the stakeholder consultation is completed, the plan document should be finalized. The nominated authorities in charge of plan development should take into account the suggestions and the strategies to resolve conflicts stemming from the previous phase. The final document should then detail all the aspects of the permitting procedures, the interaction between the national / regional plan and the municipality level plans and the directions for monitoring the results of the plan itself.

The prepared final document should be then sent to all involved stakeholders for final remarks that may be adopted or rejected in accordance with the depicted strategies, and finally sent to the political board for acceptance and promulgation. 
The resulting mining plan must be reviewed and updated and must be accepted by a broad board of stakeholders.

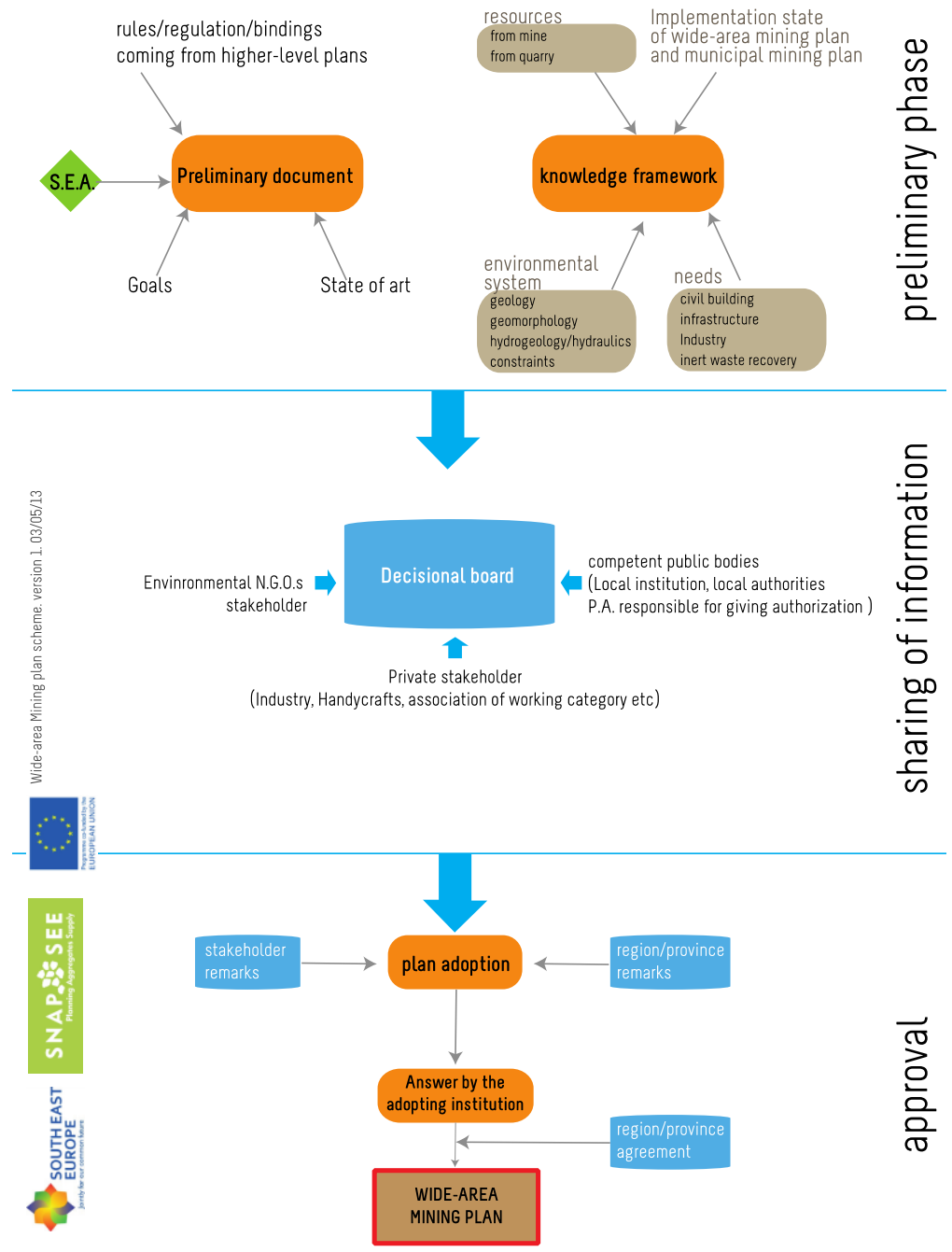

Figure 11 - A roadmap for planning 


\subsection{Plan structure}

The process of plan development must be regulated by national laws.

If not already stated by other existing laws, the decree that will give validity to the plan should at least:

- Establish the need of a (national) plan for aggregate resources;

- Establish the need to integrate the aggregate plan into a more general land use plan;

- Coordinate the aggregate plan with waste management plan;

- Establish the ownership of primary aggregates.

The process that delineates the plan should be driven by a decisional board of competent public bodies and stakeholders and should be verified by a Strategic Environmental Assessment.

In order to provide a sustainable approach, the plan should include:

- An internal coherence with the principles agreed at a European level, in order to assure a progressive homogenization of the whole region;

- The quantification of the needs of different materials in the long period (ideally more than ten years);

- An identification of the optimal areas for aggregate extraction and protection;

- An identification of alternative sources, estimation of their contribution to reduce natural resources consumption and their location in order to reduce transportation costs and impacts;

- The definition of criteria and guidelines for the location of mining areas of municipal significance;

- An assurance on the competitiveness of the aggregates industry;

- The criteria and methods for cultivation of BATs (Best Available Technologies), the final restoration of newly permitted quarries and for the restoration of abandoned quarries;

- The criteria for the post-close utilization of quarrying land, including where possible, restoration to natural and/or public use;

- The establishment of a coordination system between permitting authorities and land use planning management;

- The establishment of efficient and effective permitting procedures;

- A study of environmental balance that verifies the environmental compatibility of mining on the basis of current legislation. 
In the following pages each point will be discussed in detail and examples of text modules will be provided. The purpose of the text modules is to provide wording that can be used verbatim by authorities as they develop or revise their aggregates plans. The text represents a synthesis of, rather than direct quotes from, best planning practice wording used in various aggregates plans within and outside Europe. For a complete rationale of each element may be useful to integrate the reading with the results presented in Horváth et al. (2014) relatively to the "Vision of Best Practices for Aggregates Planning in South East Europe".

\subsubsection{Establish the need of a national plan for aggregate resources}

A national plan for aggregate resources is necessary in order to assure a sustainable supply of aggregates across generations.

A national mineral (aggregate) policy can be defined as the entirety of operations of a state for influencing supply of and demand for mineral resources on its territory.

A National Minerals Policy needs to initially develop the awareness of the society's needs for minerals, and specifically for aggregates, and in the case of aggregates of the need for access to local resources. The second really crucial issue is that it should set the supply of minerals, and specifically of aggregates, as a force for the benefit of society, and set a balanced approach in the assessment of exploration and development of extractive activities. (Tiess 2010, UEPG 2010).

- In every country at least two levels of planning should exist. The higher level, called here "National plan" refers to a plan that directs the activities in an area of at least 20-50 thousands $\mathrm{km}^{2}$ or 2-5 million inhabitants. A second level of planning, usually at the scale of a single municipality is required to ensure optimal land use and social acceptance, and it should refer to the more general plan in order to ensure national sustainability of aggregate resource supply.

- The plan for aggregates resources can be a part of a more general mineral resources plan.

\subsubsection{Integrate the aggregate plan into a more general land use plan}

Embed the mineral plan, and the aggregate resources plan, in a more general landuse plan in order to ensure access to aggregate resources, even where concurrent uses are possible.

This requirement should be fulfilled directly by land-use legislation, and inherited by the mineral plan. 


\subsubsection{Establish the ownership of primary aggregates}

The ownership of primary aggregates in SEE belongs in some cases to the state and in other countries to the landowner. Nonetheless, safe and sufficient minerals supply is a core task of the extractive industry despite that some private uses (i.e., not for commercial purposes) are frequently permitted.

In order to ensure the mining right and thus to allow a plan to easily recognize possible excavation zones, the ownership of the primary aggregates should belong to the state or to its delegates (Hamor, 2012). It should be noted, however, that it is not possible to force a country to change its regulation in order to transfer the ownership e.g. from landowners to the state since the ownership of certain commodities (including aggregates) rests in sovereign national legislation and cannot be changed by a sectorial plan (or by an EU law). When the ownership of the aggregates has to be recognized to the landowner, a specific authorization should be required in order to excavate and the authorization process should respect the priority areas identified by the plan.

\section{Example text module 1:}

The original ownership of the primary aggregate resources belongs to the local government (state, regions, provinces, counties, municipalities). Private actors can concur through public procurement in order to be granted of the license to excavate in the identified area.

\section{Example text module 2:}

The original ownership of the primary aggregate resources belongs to the landowner since the primary aggregates are classified as quarry material. In order to permit the extraction of primary aggregates, the owner should require a specific authorization, in order to balance production needs with environmental needs. This requirement applies both in the case of landowners who wish to extract personally some material from the future quarry or in the case of an area rented to a third part for resources exploitation.

\subsubsection{Reference to principles agreed at a European level}

Procedures for the definition of a sectorial plan reflect, first of all, the legislative framework of the country.

With respect to national autonomy and historical reasons that lead to different approaches in the development of mineral policies in SEE countries, future plans for sustainable aggregates management should take into account and possibly to draw 
the direction toward the EU2020 strategy since its main objectives can be considered a minimum common denominator among the goals of a sustainable development.

In many EU countries, the regional or local authorities are responsible for policy areas linked to the Europe 2020 strategy. It is crucial that all levels of governance be aware of the need to implement effectively the Europe 2020 strategy on the ground so as to achieve smart, inclusive and sustainable economic growth, and that each one plays its part in introducing the necessary changes.

\section{EU regulation that should be taken into account:}

- Waste Framework Directive 2008/98/EC and its implementing Commission Decisions

- Directive 89/106/EEC on the approximation of laws, regulations and administrative provisions of the Member States relating to construction products (amended by Directive 93/68/EEC)

- Commission Communication in the framework of the implementation of Directive 89/106/EEC (2010/C 167/01) lists 11 different CEN standards with regard to aggregates

- European Waste Catalogue

- Court of Justice ruling (C-114 Avesta case)

- Seveso II Directive amended

- Environmental Liability Directive (2004/35/EC)

- Mining Waste BAT Reference Document under IPPC Directive (BREF)

- EU Pollution Register, Mining Waste Directive

\subsubsection{Forecast of future demand of aggregate}

It is important to establish short, medium and long-term aggregate demand and supply (i.e. forecasting) scenarios in the concerned regions taking into account future supply potential including primary and secondary resources. Based on such demand and supply scenarios, aggregates land use supply concepts could be developed (including material flow analyses for different needed application).

A demand forecast can be based on expert judgment or on a quantitative model of some form. Every model will have its own level of complexity and detail, underlying theory, and implementation method. Those based on sectorial characteristics are termed bottom up models; those based on intensity of use are called top down models. Sectorial models typically represent either a hypothesized causal relationship, or are a trend extrapolation of a series of observations collected over time, i.e., time series data. The former are modelled with one, or a set of, econometric regression equations that assume demand depends on one or more independent explanatory 
variables, e.g., economic activity or population. The latter assume that the pattern of past demand will continue into the future (Agioutantis et al., 2014).

\section{Example text}

The plan assesses the likely raw material needs and having examined the various options which are available, it identifies preferred areas of working which will meet these needs. The forecast of possible future demand for minerals should inform the assessment of likely needs.

\subsubsection{Identification of priority and protection zones}

Mineral areas worthy of safeguarding are mineral areas that have no or minimal conflicts with other land use plans. They follow a traceable mineral planning process designed to avoid conflicts with raw material extraction.

The step of regional planning is especially important for the regulation of the raw material affairs. With the help of precise statements, regional plans (based on wider development programs, like national and super-regional ones) determine the regional goals of the land use planning. The plan should define the term "raw material priority zones" so that these can be guaranteed, while carefully considering the medium and long term mineral resource demands, and the limited availability of mineral resource deposits.

Developing a systematic identification and evaluation of mineral deposits with regard to their protection and worthiness should be initially carried out. This should be followed by a second phase of "conflict-elimination" to eliminate any protection conflicts caused by the mineral zones. The task of the second phase is to identify "conflict free mineral zones» taking into account other areas protected by law e.g. residential areas, national parks, water management priority zones, landscape protection areas, forests, Natura 2000 areas, etc.

In defining mineral protection zones, special attention will be given to ensure an adequate regional supply of raw building materials found close to the surface for several generations. Due to the individual groups of raw materials (i.e. sand, gravel, solid rock, high-quality carbonates, clays, industrial minerals, ores and energy raw materials) specific methods of evaluation should be developed.

When using the method of positive planning, different land use priorities may reduce deposits that are worth extracting and the remaining fields become raw material areas with priority. The advantage of this method is the fact that the authorities can apply a concrete raw material policy. A problem of the positive planning is land speculation. 
Besides that, and based on the Austrian experience, it must be mentioned that aggregates extraction may also be permitted outside raw material priority zones, i.e. in agricultural zones, if the municipality agrees. This will certainly depend on the quality of conflict management between the operator and the municipality (and concerned citizens).

\section{Example text:}

The choice of sites must take into account national policies on landscape and historic or nature conservation and on agricultural land. The plans should also safeguard mineral resources for future working. The plans should set out the development control criteria, which new planning applications for mineral extraction must satisfy.

For the purposes of the Mineral Resources Plan, raw material areas are defined as all areas which have been identified using objective and systematic analytical methods and which contain mineral raw materials. In view of expected technological advances and bearing in mind ecological and social aspects it is assumed that it will be possible to use such materials commercially in the medium to long term. Mineral areas worthy of safeguarding as defined by the Mineral Resources Plan are mineral areas, which have no or minimal conflicts with other land use plans. They follow a traceable mineral planning process designed to avoid conflicts with raw material extraction. They should be kept for the extraction of raw materials, but there should be no mandatory requirement to actually use the occurrences for mineral extraction.

\subsubsection{Identification of alternative sources}

Providing a sustainable supply mix of aggregates implies the identification of suitable secondary aggregates sources. This aspect is strictly related to the structure of a waste management plan (if it exists in the country).

In terms of sustainability, policy and legislation should be utilized in order to use secondary resources as much as possible. This, however is also a matter of recycling market structure and prices. This not only reduces the need of primary resources, i.e., prolongs the availability of natural resources for future generations, but it also reduces landfilling. Therefore, every aggregates supply concept should include appropriate tools, instruments to increase the use of secondary resources. 
Minerals planning authorities should work with other relevant organizations to use the best available information to assess the projected demand for their use, taking full account of opportunities to use materials from secondary and other sources which could provide suitable alternatives to primary materials.

\subsubsection{Definition of criteria and guidelines for local mining areas}

The plan should define the criteria and guidelines for the location of mining areas of municipal significance, based on the resources used, the forecasted demand and the factors of a physical nature and landscape protection, as well as the needs to preserve land for other uses and the protection of natural resources (e.g. underground water table).

\section{Example text:}

The municipal mining plans have been prepared on the basis of the provisions contained in the national/regional plan, and in particular those relating to the identification of priority zones.

The municipal mining plan is accompanied by an explanatory report, adequate cartography and related implementing technical standards, and identifies:

a) areas more than at the poles identified from the main floor to be allocated to mining activities, within the limits defined by law, the relative extractable quantities, as well as the location of the connected systems;

b) the final utilization of the areas covered by mining activities;

v) the arrangements for quarrying and final settlement of the same also with regard to those abandoned;

e) the methods of management;

f) measures to minimize predictable environmental impacts.

\subsubsection{Assure competitiveness of the aggregates industry}

As stated by the UEPG (European Aggregates Producers Association) there is "no construction without aggregates". As of today the aggregate industry is the most important source of raw materials (Bressi et al. 2011) and market regulation (or deregulation) is the key to assure competitiveness and to promote sustainable approaches.

Investment security for the operator is crucial. When granting mining permits for 
hard rock quarries (i.e., approved aggregates reserves), a 50-year timescale should be typically considered. No mining permits should be less than 15 years, otherwise the major capital investment cannot be justified. In any case, the duration of each permit should be evaluated taking into account the available volume of aggregates, the expected demand and the best sustainable excavation techniques available. For sand and gravel pits, the permission timescale should be 15-50 years depending on the scale of the deposit, with anticipated further renewals which should be proportionate to the scale of the deposit. The duration of mining permits should always be in line with the lifetime of the deposit: sustainability requires the extraction of the whole deposit (Cibin et al., 2011).

In that regard, some concerns may be expressed particularly in terms of non lithified deposits, like sand and gravel deposits, and the potential conflict with water supply resources, landscape preservation practices, environmental impacts reduction practices and good restoration practices. Such concerns may lead to partial extraction of a deposit.

It should be noted that the integrated use of natural and recycled aggregates, besides an appreciable saving of natural resources, could enable a better exploitation of the available resources according to the different uses.

In the free market there are a series of factors which should/could favour the use of recycled aggregates against natural ones. These include:

- a lower price than the replaced natural materials;

- the high demand for materials for road pavements, backfilling, lures, embankments etc.;

- the reduction of transport costs (which can be lower because the recycling operation is usually closer than the quarry and which can be annulled in the case of on-site production).

Low pricing is undoubtedly the most important lever in the choice of recycled product, since it represents one of the decisive factors in the granting of tenders. Furthermore governments can also develop GPP (Green Public Procurement) policies to target a broad range of goals including an increase of the percentage of recycled material consumption in many construction activities and an increase of resource efficiency. When dealing with GPPs an overemphasis on initial capital costs, for example, may cause procurement officials to favour less energy-efficient devices, even when more efficient devices would save government resources over the long run. As already mentioned this is not the case with recycled aggregates so it is a "win-win" condition.

Finally, for a partial recovery of production costs tied to the work that is necessary to 
guarantee constancy of recycled aggregates characteristics (Production Control in the Factory), the producer can also count on the fees applied to the disposal of the waste to the plant, which, even if limitedly, enables carrying out of the operation in almost every local place.

\section{Example text:}

The duration of the authorization and the relevant Convention cannot be more than fifty years, nor, as a rule, less than ten years. We recognize the need to act in accordance with the principle of sustainable development and to protect and preserve the environment: the plan will address ways to improve the environmental performance of products throughout their life cycle; this will comprise action on economic incentives for environmentally friendly products, enhancing 'green' demand through better consumer information, developing an objective basis for green public procurement, and action to encourage more environmentally friendly production procedures.

\subsubsection{Adopt best available technologies along the whole process}

Many technologies exist in order to reduce indirect impacts (related to excavation operations and transportation of aggregates) into the atmosphere, surface water and biosphere.

Usually companies invest into best available technologies when necessary to satisfy the regulatory decrees and to avoid financial penalties, issued by the law. With an appropriate education the operators may start to be an active actor in the process of a more sustainable production of aggregates. Moreover, many companies will contribute more to the local communities than legally obliged, as co-financing of sports and cultural activities or similar and maintain good local community relationship.

Quarry operators should be aware that environmental and public sound extraction is vital for the company's future. Companies today are trying, in general, to maintain the "Corporate Social Responsibility" in high levels. Consequently, business would embrace responsibility for the impact of its activities on the environment, consumers, employees, communities and stakeholders.

With regard of primary aggregate production, processing yards can obtain environmental certifications (ISO 9000/ISO 14000) based on specific technical and environmental requirements. The extraction can be done in the way that minimum amount of waste is made.

Also in the field of the production of secondary aggregates many state-of-the-art technologies exist and can be employed during the treatment of C\&DW in order to produce good quality recycled aggregates that can compete with quarry products in 
terms of technical properties. These technologies are available either in the form of mobile processing plant units that may be established on site, or as specific stationary recycling plants.

Planning instruments can provide a way to evaluate the performance of a processing plant by a set of indicators that should be evaluated at the time of the authorization.

Although this is not part of a mineral plan, it should be noted that the methodology applied for demolition affects significantly the performance of the subsequent recycling process and the technical features of the recycled products. Pre-sorting of C\&DW at source into homogeneous segments reduces recycling or disposal (where applied) costs and ensures better quality for the recycled products. This should be integrated in the waste plan in order to maximize the overall efficiency.

\section{Example text:}

The national plan defines the need for detailing municipal plans thought an explanatory report, adequate cartography and related implementing technical standards regarding the method of quarrying and final settlement of the quarries also with regard to those abandoned.

\subsubsection{Define criteria for final post-closure utilization}

Mining activities are necessarily associated with impacts on the surface. This applies particularly to the temporary utilization of the surface by opencast mines, but also for long-term or permanent utilization, such in the case of spoil heaps.

The definition of a restoration plan during the planning for future quarrying, should ensure that exhausted quarries do not become uncontrolled waste disposal sites. To ensure that a restoration plan will be activated it is necessary to secure economic resources, e.g. by guarantees.

To achieve better results on rehabilitation and restoration of exhausted sites, restoration planning should fit the specific environmental conditions of each.

If a complete recovery is not possible, the installation of recycling plants in abandoned quarries, should be considered when assessing their post-closure use. 
According to the Mining Law, mining activities do not end with the extraction of mineral resources and tipping of the overburden. Rehabilitation represents an integral part of mining activity. Mines operators are required under law to rehabilitate worked-out sites. The interests of affected communities and ecosystems are taken into account at a very early stage in the planning phase before extraction begins.

\subsubsection{Enable coordination between permitting authorities}

It might be useful to improve the coordination between permitting procedures/authorities and land use planning management. A coherent aggregates planning policy should be based on relevant data and information (the geology, the location, quantity and quality of mineral deposits are usually well known). Land-use limitation and protected areas have then to be taken into account to define the aggregate resource potential of an area. Once the source potential is estimated, a precise knowledge in terms of aggregates demand, information on the amount of the produced aggregates, and information on recycling rates at district level is required to finalizing the plan; however, this data require a strong coordination between different authorities.

Furthermore, the law should not generate overlapping administrative responsibilities among different planning authorities. From a hierarchical point of view, a local plan should clearly fit in the national plan framework.

Usually the principal plan should deal with demand/offer forecasts, import/export and cross-boundary issues, economic, social and environmental balance as well as a strict relation with land-use planning e.g. in the definition of «aggregates priority zones».

Some aspects, relevant for SARM and SSM should be part of National/Regional Mining Legislation (and be reflected into the plans), including:

- Resource efficiency, i.e. avoiding waste;

- Use of best technical environmental standards;

- Concepts of transport according municipality traffic principles;

- Guaranteeing funding for restoration;

- Particularly consideration of land use planning in permitting procedures;

- Public interest -that must be considered at a broader level.

Municipality mining plans will describe in more detail the framework defined by the plan and, in a decentralized approach, these plans finally identify the areas potentially suitable for exploitation by private entities. The restoration plan usually includes an environmental impact assessment and some measures to reduce impacts. 
The Municipal [aggregates] plan is prepared based on the provisions contained in National Plan, and in particular those relating to the extraction in the aggregates priority zones. The Municipal plan is adopted and approved with the procedures provided for general planning schemes; advisory body is in this case the [national] technical Commission for mining activities.

It established the [national] technical Commission for mining activities with advisory duties in the cases provided by the Law.

The Commission holds office for five years and is composed as follows:

a) by the regional council or that has jurisdiction in this matter, acting as Chairman; the commissioner may, in his absence, be replaced by a deputy, chosen among the members of the Commission itself;

b) by five experts in the disciplines of geology, mining, agriculture and forestry, economic, legal, environmental planning and urban-territorial, appointed by the Regional Council between academics and technicians with proven scientific expertise and professional experience;

c) by three experts in the same disciplines, chosen by the Regional Council of the employees in service with regional powers inherent in the materials.

\subsubsection{Permitting procedures should be efficient and effective}

A one-stop shop approach is proposed, where all involved departments coordinate efficiently with each other. Also it is assumed that permitting procedures will be based on land use planning and management at least in terms of the selected raw material priority zones.

From a planning point of view, legal exceptions do not facilitate the identification of areas suitable for excavation and should be avoided where possible.

\section{Example text:}

The exercise of the mining activity is allowed with provision authorizing the Mayor [or other Authority], exclusively in the areas specified in the Plan of mining activities, on the advice of the Technical Commission for mining activities, and after the definition of a convention between the concessionaire and the State. 


\section{Example of exception:}

There is an exception case, consisting in aggregate extracting resources situated in areas classified as state property for the legislation, (the state property is movable or immovable property belonging to local governments, namely the state, regions, provinces and municipalities). These aggregates are therefore property of the public entity holding the land ownership, usually a lake, a river or its banks. In this case the local government, that can grant exploitation in certain cases and under certain conditions (e.g. as by-products of protection and hydraulic interventions, aimed at a functioning water system or the watercourses' remediation).

\subsubsection{Enforce the need for an environmental balance}

The plan should integrate the environmental impact assessment (EIA) into the skeleton operations plan procedure with specific provisions taking into account the dynamic character of mining activities. The plan should contain a list of possible mining projects that will be subject to an EIA (according to the size or the volume to be excavated). In order to guarantee the participation of the public and of all stakeholders, the approval of a skeleton operations plan with an EIA by the mining authority is subject to a formal plan approval procedure, with a concentration of all involved parallel permits (one-stop shop). This procedure allows all issues involved to be examined with all administrations and stakeholders and gives the investor the necessary legal security.

\section{Example text:}

All the extraction projects must be subjected to the procedure of EIA if they concern quarries with more than $500,000 \mathrm{~m}^{3} /$ year of material extracted or an affected area greater than 20 ha. 


\section{References}

Agioutantis, Z. et al. (2014). Handbook on Data and Analysis Methodologies for Aggregates Planning: A joint manual for planning authorities in SEE region, SNAP-SEE.

Cibin, U., Cera, M.C., Spotorno, C., Furin, S., Pelosio, A. , Romagnoli, M., Rizzati, A.R. \& Maras$\mathrm{mi}$, C. (2011). SARMa Activity 4.2 (SSM) Synthesis Report. http://www.sarmaproject.eu/uploads/media/SARMa_Report_Sustainable_Supply_Mix_0 1.pdf

Council Directive 89/106/EEC of 21 December 1988 on the approximation of laws, regulations and administrative provisions of the Member States relating to construction products. Official Journal L 40, 11.02.1989, p. 12-26. http://eur-lex.europa.eu/legalcontent/en/ALL/?uri=CELEX:31989L0106

CSES 2014. Final Report on "Evaluation and Exchange of Good Practices for the Sustainable Supply of Raw Materials within the EU" - ANNEX A - GOOD PRACTICE CASES. Centre for Strategy and Evaluation Services. http://ec.europa.eu/DocsRoom/documents/4878/attachments/1/translations/en/renditi ons/pdf

Dolinar U., Softič M. \& Kozinc Z. (2014). Handbook on Consulting Stakeholders when Applying Best Practices in Sustainable Aggregates Planning, SNAP-SEE, 2014

EC (2011). Resource-efficient Europe - MEMO/11/43 26/01/2011. European Commission. http://europa.eu/rapid/press-release_MEMO-11-43_en.htm?locale=en

Hámor, T., Tiess, G., Kager, J. \& Heimburg, J. (2011). European Community Law relevant to aggregates: SARMa - Review of EU Community Legislation - A framework recommendation. http://www.sarmaproject.eu/uploads/media/SARMa_Report_EU_Law.pdf

Hámor, T. (2012). Recommendations for effective aggregate policy and management, covering the legal and regulatory solutions with regard to sustainable aggregate resources management.

http://www.sarmaproject.eu/uploads/media/SARMa_Recom_Aggreg_Policy_01.pdf

Horváth, Z., Miko, S., Sári, K. \& Dedić, Ž. (2014). A Vision of Best Practices for Aggregates Planning in South East Europe, SNAP-SEE, Ljubljana, $56 \mathrm{p}$

IISD (2004). National Strategies for Sustainable Development: Challenges, Approaches and Innovations in Strategic and Co-ordinated Action. International Institute for Sustainable Development. IISD, Winnipeg, CA.

Tiess, G. (2010). Minerals Policy in Europe: Some Recent Developments. Resour. Policy 35, 190-198.

UEPG (2010). Planning Policies and Permitting Procedures to Ensure the Sustainable Supply of Aggregates in Europe. http://www.minpol.com/LeobenReview_final-final_060610.pdf

Weber, L. (2012). Der Osterreichische Rohstoffplan Archive fur Lagerstattenforschung 26, 264 S. Geol B-A, Wien (The Austrian Mineral Resources Plan). Arch. f. Lagerst. forsch Geol. B.A. Band 26, pp. 1-264. Wien. http://opac.geologie.ac.at/wwwopacx/wwwopac.ashx?command=getcontent\&server=im ages\&value=AL0026_001_A.pdf 



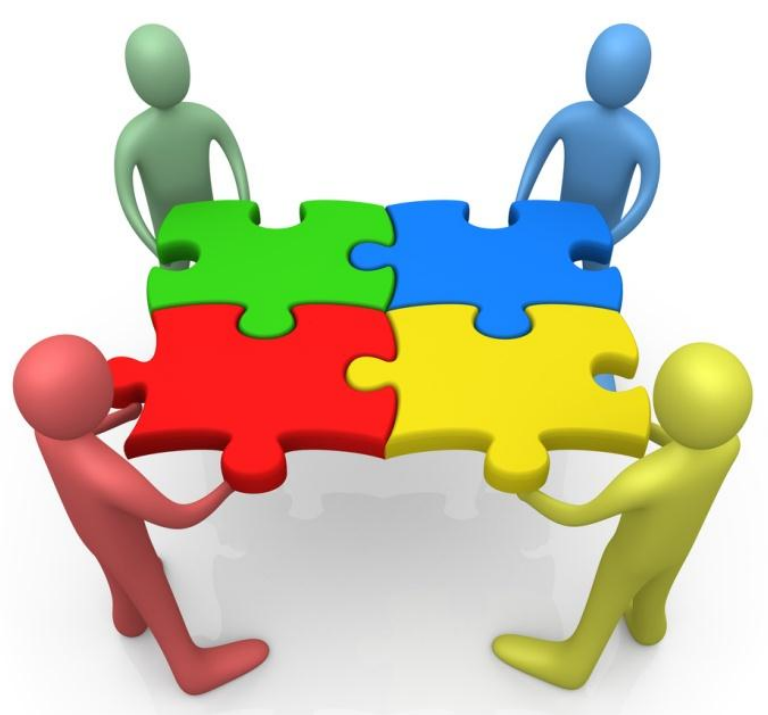

Sustainable Aggregates Planning in South East Europe (SNAP-SEE)

http://www.snapsee.eu 